\title{
Importance of Palliative Care in Pediatric Oncology
}

Jael Rúbia Figueiredo de Sá França1, Maria Emília Limeira Lopes, Marcella Costa Souto Duarte ${ }^{2}$, Gilvânia Smith da Nóbrega Morais ${ }^{3}$, Eliane Cristina da Silva ${ }^{1}$, Ana Aline Lacet Zaccara1, Thaís Costa de Oliveira1, Kalina Coeli Costa de Oliveira Dias', Maria de Fátima de Oliveira Coutinho'

\section{Abstract}

To analyze the testimonies of clinical nurses about the importance of the practice of palliative care in Pediatric Oncology, in the light of the Humanistic Nursing Theory. This is a qualitative research conducted with ten nurses from a pediatric unit of a public hospital in the city of João Pessoa - PB, through a semi-structured interview, using Paterson's and Zderad's Humanistic Nursing Theory as theoretical and methodological support. The following categories emerged from the analysis: palliative care is essential for promoting humanized care of children with cancer, in end-stage; and palliative care value the communication among nurses, child, and family. It is concluded the need for the promotion of humanized practice by nurses, both the child under a palliative care, as the family, showing to be motivated, sensitized and respecting them in their uniqueness and authenticity, as preconized by the Humanistic Nursing Theory.

\section{Introduction}

Childhood cancer is rare, however, for the past year, has constituted the leading cause of death among children [1]. Cancer and its treatment bring repercussions for the child life and their family, causing a variety of symptoms and difficulties, and impose changes in habits, restrictions, isolation, removal of routine activities such as playing, lack of contact with friends, recurrent hospitalizations, even after the acute phase of treatment, which cause intense pain [2]. It should be noted that the international literature shows that we still need more studies about how to deal with different and varied symptoms of children with cancer [3].
1 Universidade Federal da Paraíba, Paraíba, PB, Brasil.

2 Centro Universitário de João Pessoa Paraíba, PB, Brasil.

3 Universidade Federal de Campina Grande Paraíba, PB, Brasil.

Contact information:

Ana Aline Lacet Zaccara.

झ anazaccara@hotmail.com

Keywords

Palliative Care; Oncology; Pediatric Nursing; Nursing Theory. 
However, due to the incorporation of new technologies, uses of treatments, increasingly effective, and the development of several pediatric subspecialties, the survival rates of these children are increasing. Even so, a considerable number of children with cancer will not get the illness cure and will receive palliative care until their end-stage [4].

Palliative care constitutes an integrated and multidisciplinary therapeutic modality of total care, active and full, given to the patient whose disease no longer responds to curative treatment. With an emphasis on a holistic approach, such care turn to the promotion of comfort, relief of pain and symptoms associated with the disease in a highly specialized approach, attendance to the biopsychosocial and spiritual needs of the sick and support for family members who share this process and the final moment of the life of their loved one. [5]

In the field of Nursing, the value of palliative care for the patient's care promotion without a therapeutic possibility of cure is undeniable, especially for children with cancer. Therefore, it is essential the nurse use of a Nursing theory subsidizes its assistance to children with cancer, for example, the Humanistic Nursing Theory. Such a theory is understood as a living dialogue that involves the meeting, the presence, the relationship, a call and an answer, which are presented as verbal and nonverbal communication, being the basis of relational care, according to the relationship between nurse and client aiming at the welfare and being better for the patient who participates as an active subject of the process and seeing in the nurse, help and support possibilities for coping their health problem [6].

Therefore, the nurse, providing palliative care to children with cancer, guided by the cited theory, should have the understanding that such care mean preserving their physical, moral, emotional and spiritual integrity through an objective and flexible assistance, which values the different worlds: an inner world (I) and other external (YOU), where YOU is present. Both describe the special features of re- lating to each other: the I-YOU relations (subjectsubject), I-THIS (subject-object) and I-US (subjectcommunity) [7].

Based on this understanding, the I-THIS relationship is expressed as a man reflection about their I-YOU previous relationships. Reflecting on these relationships, it is valued as an object to be known - the THIS. The I-US relationship enables man to acquire their identity, through its relational situation, relieve symptoms and promote personal growth of the patient, the family, and the nurse [7].

Nevertheless, the importance of the assistance of nurses in the practice of palliative care for children with cancer, when grounded in the Humanistic Nursing Theory, emphasizes the need to move forward on new research to deepen this theme, since the studies in the national and international literature in Nursing are scarce $[6,8]$.

This time, the proposed study contributes to and advances in the area of palliative care in Pediatric Oncology from the perspective of nurses, in the light of the Humanistic Nursing Theory. To this end, this research was conducted by the following question: which is the understanding of clinical nurses about the practice of palliative care in pediatric oncology?

Given the above, this study aimed to analyze the testimonies of clinical nurses about the importance of the practice of palliative care in Pediatric Oncology, in the light of the Humanistic Nursing Theory.

\section{Method}

This is a field research to address the qualitative aspects of the investigated phenomenon, using the Humanistic Nursing Theory proposed by Paterson and Zderad, based on existentialism and phenomenology. Moreover, to allow a better understanding of the study design, the collection of empirical data, analysis and interpretation of data, the criteria consolidated into the Consolidated Criteria for Reporting Qualitative Research (COREQ) were considered in this study [9]. 
The setting of the investigation was the Pediatric Oncology Clinic of a public hospital, localized in the city of João Pessoa - PB, considered as a reference in the treatment of cancer in children and adolescents, from zero to nineteen years old, as well as adults in this State.

Importantly, the Clinic mentioned above is in a process of implementation of the Systematization of Nursing Assistance (SNA) of children with cancer and their families, such as standardization of care for this clientele and is already providing care as preconized by the SNA. It should be noted that it does not present the use of Nursing Theories basing care on this population.

Concerning a structured palliative care service, it is important to note that the aforementioned Clinic does not consider this service, but meets the guidelines recommended by the World Health Organization, about the care provided to children outside the therapeutic possibilities of cure, and promotes Palliative Care.

Ten clinical nurses of this institution participated in the research. Participants were selected by convenience sampling, considering the following inclusion criteria: professional practice for at least one year of the unit, availability and being in professional activity during the data collection period.

It should be noted that the first contact with the nurse participants of the research occurred before the empirical phase of the study. The relevance of the research project, as well as goals and research procedures, were reported by lead researcher, in a face-to-face meeting, organized by the nursing coordinator, to the elected institution for research.

It is noteworthy that, being a research involving human subjects, the ethical principles of Resolution 196/96 were followed, of the National Health Council (NHC)/Ministry of Health $(\mathrm{MH})$ in force in the country, at the collection period data, as well as the Resolution 466/2012 of NHC/MH currently in vigor. Thus, the project was approved by the Research Ethics Committee of the University Hospital
Lauro Wanderley of the Federal University of Paraíba under the Protocol n 062/10.

Data collection occurred from October to November 2010, at the Pediatric Oncology Clinic, with nurses, through semi-structured interview technique. These interviews were recorded using the recording system to capture, with reliability, the participant testimonies, and transcribed in full, for further analysis. The semi-structured interview was conducted with the following guiding questions: what do you understand by palliative care? Which strategies do you use to promote palliative care in children with end-stage cancer? What do you think about the communication as a tool to assist the children with end-stage cancer? How do you use communication to assist the child with end-stage cancer?

To preserve the anonymity of nurses inserted in the study, the researcher used to characterize them the letter " $\mathrm{N}$ " followed by numbers from one to ten. Example: the first professional "E1"; the second "E2", and successively. The empirical material obtained of nurses reports was qualitatively analyzed, and then analyzed in the light of the Humanistic Nursing Theory considering the five phases of Phenomenological Nursing - since this Theory is based on the Phenomenology - applied in the description of the experienced dialog, existentially, between the researcher and the nurses participants of the study, elucidated below [7].

Researcher preparing to meet. The researcher sought to reflect about their way of being and acting in front of the healthcare practice of the nurse and open up to unique experiences shared in authentic dialogue. To this end, they performed the reading of literary works, knowledge of films that focused on the essence of the human being and their diverse ways of perceiving and relating to the world.

The researcher intuitively knows the other. Inserted in the field of study, the researcher devoted to the self-process, from the US-YOU relationship with the nurses of the Pediatric Oncology Clinic. 
Initially, they sought to hear the nurses about various everyday affairs; being directed to the practice of nursing care, or even relevant to personal and family spheres.

The researcher knows, scientifically, the other. In this stage, the interview that lasted an average of thirty minutes by respondent was held. It is appropriate to emphasize that, with the intention of recording the time of the interview, the researcher made notes in the field diary.

The researcher synthesizes, in a complementary way, the known realities. At this stage, it proceeded to the several, successive and attentive individual readings of each, from a thorough coding of each interview, to carefully study them to interpret, categorize and add knowledge of the experiences of the previous phases, comparing their conformity and distinctions, and synthesized the experienced phenomenon to apprehend in a comprehensive way. This step was developed concurrently with the collection of empirical data. Two researchers with experience in qualitative studies participated in this process besides the main author of the work.

Multiple successions to the paradoxical unity of internal nursing process. This process steps evolved from the description of the phenomena experienced by clinical nurses of the Pediatric Oncology Clinic. At that moment, the researchers expanded their point of view, conscious of the multiple presented realities, considering its relations through reflection and analysis, to better understand the phenomenon under investigation, from the confrontation with the specific literature for the study. The three researchers named in the earlier stage participated at this stage.

\section{Results}

Following are the subjects of categories, obtained from interviews with ten nurses who participated in this research, analyzed based on the Humanistic
Nursing Theory: palliative care are essential to the promotion of humane care of children with endstage cancer; palliative care value the communication between nurses, children, and their families.

\section{Palliative cares are fundamental to the promotion of human assistance to children with end-stage cancer}

Nurses focus on palliative care as promising a dignified death to the child, in a human way, in the world of care, giving life a fundamental value of the human being, valuing their rights, particularly about the importance of dying with dignity, as stretches of exposed reports:

[...] Palliative care for the child, for me, is to provide a dignified death, [...]. In this sense, we have to support the child, minimize their suffering before their pain.

You have to surrender truly to care. What we can do to perform it in some way, we do.

[...] Be aware that we are there, in the last moments of his life, those moments have to be worthy and that we are there, dealing with a being like us, and it could be us. Then, with great dignity, [...].

\section{N3.}

Palliative care for the child who experiences the moment of finitude is directly related to you give her a death without suffering, involving a care that respects their freedom and recognize their dignity, [...].

The speeches of the nurses retract, emphaticaIly, that palliative care of children with cancer are grounded in the idea that this, even at end-stage, is not just a physical body, to which nothing can 
be done, but a person able to make life a growth experience and realization. Therefore, nurses should promote a humanized care, based on the attendance of their basic needs. Therefore, a practice that favors an approach that contemplates it, from an authentic I-YOU relationship, must start with its admission to the Pediatric Oncology Clinic until their finitude.

Accompanying the child in the process of terminal life, nurses suffer and are concerned with the preservation of the physical image of the child, before the effects of treatment, which requires attentive care, with death as a constant presence that brings out the sense of loss. The nurses also express respect for their disease, elucidating the importance to explain everything that is happening, leaving them comfortable, since this child are out of their everyday life and goes to experience the unknown. The following lines explain this reality.

[...] It is important to explain to them what is happening, being able to have more security in the care we give to them. I suffer a lot because at any moment they can die, is difficult.

[...] We have to respect, preserve the image of the child, explain to them what's going on, makes them comfortable.

For this, we must have general knowledge of the cancer type, especially when it is no longer healing and employ palliative care, because we are afraid when we don't have that specific knowledge.

About the comfort necessary to minimize the suffering of children with cancer in palliative care, it is worth noting that nurses develop direct contact with this, in the certainty that the child can actively participate in their care. This can be achieved from the clarification of the procedures to be performed, showing their importance for treatment continuation, respecting the uniqueness of each child, through an open and frank dialogue, in search of a better quality of life to the last days they have, according to the following reports:

[...] At the time that the child does not accept the treatment, I try to leave them there alone, [...]. Then, if they do not accept, when we get back, we'll talk and trying to find a way to do the procedure, minimizing their suffering

I try to show them that the procedure is important for continued treatment. All this through dialogue, attention, and affection, doing the best to improve their quality of life while respecting their moment.

\section{Palliative care value the communication between nurses, child, and their family}

In this communication, it is clear that childcare is provided and efficiently materialized. Therefore, it is essential to seek effective alternatives to meet their specific needs through a comprehensive care that brings together professional expertise to human ability, reflected in the caring tract and zeal attitudes, interest, and appreciation of the other. This fact is elucidated in the following speeches:

Sometimes, when we take a bath, and the mother says, "No, not now! Look! She asked not to bathe now" Then we say: Ok! So, soon we give a bath, let her awake. This, for me, is a therapeutic communication.

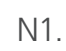


[...] So, we have to attend to the mother's request: then it's ok! [...]. We have to respect this moment of life of the child and respect the suffering of their family, especially the mother. We must have good communication with the child and their family and so provide humanized care

In the above-referenced testimonies, it is noted that the nurse associates the comfort promoting for the requests from the child-family binomial, easing the health service routines and even make technical the profession in adaptation to the child's individual and the mother needs and to the time of terminal life, through good communication.

Considering that palliative care to children with cancer and their families must be permeated by an effective communication process between the nurse, the child and being an accompanying mother, has a direct impact on the quality of service provided by health institutions and how this is perceived by the user, the nurse should provide appropriate clarifications to mothers and their children about the disease, treatment, and prognosis, passing truthful, clear and objective information concerning the technical issues to provide more choices, participation and adherence to therapy.

[...] I communicate when conducting an examination or an invasive medical procedure, to ease the anxiety of both mother and child because they want to know the truth.

N3

So we try to talk, dialogue, saying that it does not hurt, that will be better, will not dry out. So, we have to comfort the child and their family, so they can participate in their child cares decisions and authorizes certain procedures.

N4.
As for the information regarding the child health status, in general, nurses recognize that the family has the right to be informed about the aspects related to the disease process, and that involves diagnosis, clinical examinations, treatment, and prognosis. However, facing a bleak prognosis, nurses experience a dilemma, related especially to the omission of information, as shown in the following statements, constituting a communication failure.

[...] The family has to know the illness state of the child. However, we must have the wisdom of how far we can go, [...].

[...]. Whatever I can do to comfort and help, to try to clarify, I'm going to do, so that the family does not suffer so much.

When I see that I cannot, everything has its limits. I think we need to have limits because there are many doubts, many questions; they have no explanation, and they want us to give the answer; and this anguish us a lot. We sometimes have that answer, but cannot give.

In these statements, nurses express that the communication process becomes impaired contributing to the health team, with an emphasis on nursing, incurring failures related to fear as the lack of support for communicating difficult news.

\section{Discussion}

Considering the importance of palliative care in Pediatric Oncology, with the Humanistic Nursing Theory as a foundation, we highlight the following important aspects of the study of the National Oncology Institute in Cuba, which addressed the palliative care and death in pediatric oncology [10]. In it, such a situation is described as a harrowing 
experience since, before the child's fragile condition, to provide dignified death, it is necessary medical treatment of excellence at the end of life, directed to the benefits of the natural evolution of the disease and about socio-cultural aspects, physical comfort, and well-being, as explicit the previous testimonies.

Accordingly, palliative care has the objective of promoting the humanization of the finitude of life, led by the ethical principles of respect for human life and providing a die with dignity. Therefore, the dignified death is a result of palliative care and must, therefore, submit insertion and continuity in philosophical principles that address the ethics of respect for human beings - Bioethics. This ensures the primacy of palliative care since it provides to children with cancer and their families a better quality of life, immediately after diagnosis, guaranteeing them better physical, emotional and social sizing, during and after treatment [11].

Therefore, it is the nurse responsibility to understand the process of death and to die, to be able to help the child in their finitude. This aid relationship allows entering the child's world, knowing them, respecting them and loving them. A study developed by doctor nurses in palliative pediatric oncology showed that the practice of palliative care for children with cancer should be recognized as a priority ahead of the experienced situation and meets the specific theoretical and practical approaches to such care. [12]

In the Humanistic Nursing Theory, the nurse should promote care, by their life experience through an interrelationship person to person, emphasizing as important as the act of caring, is to be attentive to the effects that this care produces in patients, being truly present, in search of being better. To achieve the being better, it is essential to advocate respect for the dignity and rights of human beings, sharing their existences, experiences, perceptions and feelings. [7]

Studies with clinical nurses in palliative care at the Pediatric Oncology, based on the Humanistic
Nursing Theory, showed that the impact that cancer causes in the child's life is very significant, especially when it has no more therapeutic possibilities of cure due to unavoidable disruptions and changes in their daily lives and the possibility of evolution of death $[6,8]$. In this conception, the nursing care in Pediatric Oncology requires knowledge and skills that go beyond the technical and scientific knowledge, acquired at the same time, the sensitivity to deal with these children, with the support to explain and guide them about their illness, their treatment and care, verbalizing their autonomy and recognizing their limits from an ethical act.

In this light, the results of this study relate to the cited theory, which occurs from an inter-subjective relationship (be and do with), in which are included the meeting, the presence, the relationship, a call and an answer, exemplified in the practice of taking care of the nurse with the child. From this perspective, the Nursing aims to ensure the being better and be the patient's well-being through inter-human relationships. [7]

Therefore, the effective communication between all involved in the care results in improved children's well-being and their family. [13] A study performed in an Oncology unit in Hong Kong, with nurses and family, corroborates the results of this research, when it mentions the need to communicate authentically with the patient out of healing therapeutic possibilities, propitiate the personal growth of everyone involved in care [14].

Thus, the relationship must be established between the nurse and the child with end-stage cancer, based on the understanding of the meanings that the nurse assigned to provide palliative care to that child, involving an authentic presence, available to be with each other, understand them and help them, from a lively dialogue in which there are shared calls and answers, as elucidates the Humanistic Nursing Theory.

Based on these, at the Pediatric Oncology Clinic, it is necessary for the nurse to be available and 
accessible to promote the care of children with cancer without therapeutic possibility of cure, based on palliative care, understanding it intuitively, from the inter-subjective transaction, relating to the way of being of each child involved in the relationship of care, from authentic communication.

The authentic communication is an active process of engagement between people, which establishes, among other ways, through dialogue [8]. It is a therapeutic intervention instrument that minimizes the suffering of the experience of children with cancer under palliative care [11].

It is worth noting that in pediatrics, nursing assistance must involve the children and their families, considering this binomial a single core care, including also in this process, the relational and social world that surrounds them. In these terms, the communication is presented as an integral element of a humanized care of the child-family to mediate and facilitate changes in a real therapy encounter [15].

Regarding the importance of the family for children with cancer, studies have shown that the welfare of the child is strongly related to the welfare of their parents, since those suffer throughout the course of the disease [16-17].

A study of nurses in the care of children with cancer, in palliative care, based on the Humanistic Nursing Theory, pointed out that the palliative approach involves the establishment of an inter-subjective transaction embodied in an existential encounter between those who care and who is cared. This allows the individual, apart from the therapeutic possibilities - in this case, the child - to share their feelings, sufferings, pains, and weaknesses, so that the assistance that the nurse gives to the child and their family is facing to the care of their well-being and being better, since it attaches to these children life, the opportunity to be more, respecting their living moment [6].

The use of the Nursing Humanistic Theory in patient care is understood as a communication process between the caregiver and the cared for, respecting their limits and potential [7]. Therefore, according to reports expressed by study participants is important to provide information about the procedure to be performed and to clarify that will respect the limits of the little patient, to minimize fear and anxiety resulting from the unknown. Moreover, it is necessary to communicate real information to print confidence, allowing including that the child and family to feel happy and secure. In this scenario, a study about the Humanistic Nursing Theory reveals that the essence of this theory is the appreciation of the existential experience of the human being in their care process [18].

A study of fifteen children with cancer at university hospitals in southern Sweden showed that the nurse must establish a dialogue with these children by building friendships, exchange of experiences, building trust, respect to their individual needs and mutual understanding, minimizing their anguish imposed by the disease and hospitalization [2]. In this care, the presence of the nurse dedicated to the child is characterized by the I-US relationship (child, family, nurse) represented by the commitment of all those involved in assistance, which provides the real encounter of care in the fight for the well-being of the patient.

Nevertheless, by the fact that the child is a minor, it is necessary to perform some procedures, being authorized, inexorably, by their legal guardian represented, often, by their mother. This assumption is provided by Resolution No. 41/95 of the National Council for the Rights of Children and Adolescents, in its art. 10, which determines and supports the responsibility of parents or guardians to participate actively in the diagnosis, treatment and prognosis of their child, getting all the relevant information about the expected procedures [19].

Therefore, seeking to respect the autonomy of parents and child, the nurse must strive, for a genuine relationship, developing a shared care with family, establishing an ethical commitment before making decisions about the treatment of children 
with cancer under palliative care, based on the Humanistic Nursing Theory.

However, it is recommended that each case is individually weighed, to consider the family as a fundamental part of palliative care for children, and being also responsible for decision-making for each direct care provided to the child at the time of hospitalization. Also, the children that need palliative care are entitled to receive it as the best option for better quality of life to the last days they have [10].

A study with ten nurses specialized in Pediatric Oncology in Colombian hospitals and regions of the country showed that the deaths of children with cancer, generate a large impact on their lives, bringing them frustration and is a major challenge for these professionals, before the experienced situation. And yet, the experiences of the nurses in caring for these children transformed their professional care in a loving, unique and comprehensive care, both to the child and their family. [20]

The nurses, who work with palliative care in Pediatric Oncology, should have as support of these care, the use of the Humanistic Nursing Theory. By taking care of the child's family, the professional should include to this care, the attendance of their special needs, concerns, anguishes and fears since both the child and their family are going through an adjustment period. This attention is important since the way the child is facing the disease, and the possibility of death depends on previous experiences of their parents, the family structure, among others.

\section{Conclusion}

By analyzing the statements of the nurses participating in this study, we found that palliative care for children with cancer in end-stage was considered by them as fundamental to the promotion of human assistance to this being who experiences terminally. Such assistance presupposes a practice that favors an approach that contemplates the I-YOU authentic relationship, between nurse and child, and that values their rights, particularly those related to meeting their basic needs and promoting a dignified death. It should be noted that the latter constitutes a challenge for nurses since it includes the balance of hopes and needs of the child, the family, and the professionals.

The testimonies highlighted the communication between nurses, child, and family as essential to palliative care, since it facilitates the identification of the child's needs, minimizing the fear and anxiety during procedures, prints trust in child-family binomial, and promotes greater participation and adherence to treatment. Also, effective communication between nurses, child and family have a direct impact on the quality of service provided by the health institution and how the user perceives this service.

The study presents some limitations, such as a small number of participants, which makes it impossible to generalize the results, and reveal a care practice in a specific context. However, suggests possibilities for palliative care to be better understood and adopted by nursing assistants, especially if it is based on the Humanistic Nursing Theory, which is an essential foundation of communication as the basis for relational care, for the well-being and being better for the client. It is recommended to perform further studies to raise the expansion of knowledge about the practice of nurses in palliative care in Pediatric Oncology, based on the Humanistic Nursing Theory. 


\section{References}

1. Thienprayoon R, Lee SC, Leonard D, Winick N. Hospice Care for Children With Cancer: Where Do These Children Die? J Pediatr Hematol Oncol. 2015.

2. Einberg EL, Svedberg P, Enskär K, Nygren JM. Friendship Relations From the Perspective of Children With Experience of Cancer Treatment: A Focus Group Study With a Salutogenic Approach. J Pediatr Oncol Nurs. 2015; 32(3): 153-64

3. Arland LC, Hendricks-Ferguson V, Pearson J, Foreman NK, Madden JR. Development of an in-home standardized end-oflife program for pediatric patients dying of brain tumors. J Spec Pediatr Nurs. 2013; 18: 147-55.

4. Piva JP, Garcia PCR, Lago PM. Dilemmas and difficulties involving end-of-life decisions and palliative care in children. Rev Bras Ter Intensiva [Internet]. 2011 [cited 2015 Mar. 20]; 23:(1) 78-86. Avaliable from: http://www.ncbi.nlm.nih.gov/ pmc/articles/PMC2913812/

5. Almeida CSL, Sales CA, Marcon SS. O existir da enfermagem cuidando na terminalidade da vida: um estudo fenomenológico. Rev Esc Enferm USP. 2014; 48(1): 34-40.

6. França JRFS, Costa SFG, Andrade CG, Costa ICP, Souza ATO, Duarte MCS. Nurses' experience in caring for a terminally ill $C$ hild: study in the light of the humanistic nursing theory. Cienc Cuid Saude. 2014; 13(3): 425-32.

7. Paterson JG, Zderad LT. Enfermería humanística. México (DF): Limusa; 1979

8. França JRF, Costa SFG, Nóbrega MML, Lopes MEL, França ISX. The importance of communication in pediatric oncology palliative care: focus on Humanistic Nursing Theory. Rev Latinoam Enferm. 2013; 21(3): 211-7.

9. Tong A, Sainsbury P, Craig, J. Consolidated criteria for reporting qualitative research (COREQ): a 32-item checklist for interviews and focus groups. Int J Qual Health Care. 2007; 19(6): 349-57.

10. Abreu MCL. Interdisciplinary approach to quality of life and death in Oncopediatrics. Rev Cubana de Enferm. 2011; 27(1): 98-105.

11. Hamner T, Latzman RD, Latzman NE, Elkin TD, Majumdar S. Quality of life among pediatric patients with cancer: Contributions of time since diagnosis and parental chronic stress. 62 ( $7^{\text {th }}$ ed.). Wiley Online Library: 2015. Pediatric Blood \& Cancer; 1232-36.

12. Hendricks-Ferguson VL, Akard TF, Madden JR, Peters-Herron A, Levy R. Contributions of Advanced Practice Nurses With a DNP Degree During Palliative and End-of-Life Care of Children With Cancer. J Pediatr Oncol Nurs. 2015; 32(1): 32-9.

13. Care Coordination. Agency for Healthcare Research and Quality. U.S.: Department of Health \& Human Services; 2014.

14. Chan HY, Lee LH, Chan CW. The perceptions and experiences of nurses and bereaved families towards bereavement care in an oncology unit. Support Care Cancer. 2013; 21(6): 1551-6.
15. Martinez EA, Tocantins FR, Souza SR. The specificities of communication In child nursing care. Rev Gaúch Enferm. 2013; 34(1): 37-44.

16. Shonkoff JP, Garner AS, Siegel BS, Dobbins MI, Earls MF, McGuinn $L$, et al. The lifelong effects of early childhood adversity and toxic stress. Pediatrics. 2012; 129: E232-46.

17. Zwiers A, Campbell C, Evans M, Kirkwood K. Constructing the Meaning of Survivor With Former Pediatric Brain Tumor Patients. J Pediatr Oncol Nurs. 2015; 32(3): 143-52.

18. Morais JSN, Costa SFG, Carneiro AD, França JRFS, Nóbrega $M M L$, Duarte MCS. Scientific production about the theory of humanistic nursing: Integrative review. Rev enferm UFPE on line [Internet]. 2014 [cited 2015 Apr. 20]; 8(1): 137-4. Avaliable from: http://www.revista.ufpe.br/revistaenfermagem/index.php/ revista/article/view/4810/pdf 4446

19. BRASIL. Conselho Nacional dos Direitos da Criança e do Adolescente. Resolução n. 41. Brasília, 1995.

20. Vega-Vega P, González-Rodríguez R, Palma-Torres C, AhumadaJarufe E, Mandiola-Bonilla J, Oyarzún-Díaz C, et al. Develando el significado Del proceso de duelo en enfermeras(os) pediátricas(os) que se enfrentan a la muerte de un paciente a causa del cáncer. Aquichan. 2013; 13(1): 81-91.

\section{Publish in International Archives of Medicine}

International Archives of Medicine is an open access journal publishing articles encompassing all aspects of medical science and clinical practice. IAM is considered a megajournal with independent sections on all areas of medicine. IAM is a really international journal with authors and board members from all around the world. The journal is widely indexed and classified Q1 in category Medicine. 